\title{
Renewable energy sources for historic buildings: the Crucifers Convent in Venice
}

\author{
L. Schibuola \& C. Tambani \\ Department of Design and Planning in Complex Environments, \\ University Iuav of Venice, Italy
}

\begin{abstract}
The design of historic building conservative restoration based on EcoArchitecture principles is the theme considered here. The recovery of buildings subjected to preservation in order to use them for modern functions is a widespread problem in many old European cities. This exigency arises from the observation that often only a real utilization justifies the costs of the refurbishment and of the following maintenance work. But the existing restrictions usually prevent working on the building envelope to reduce the energy demand. However, the sustainability of the restoration cannot ignore the strict requirements about energy consumption and management cost reduction. It is therefore necessary to focus the intervention on the energy efficiency of the plants taking the opportunity to exploit the renewable energies even more than in new buildings. The case of the former convent of the Crucifers in Venice is presented here. The lagoon environment suggests the use of the surface waters coupled with a heat pump as renewable energy source. The modeling of the building-plant system and the consequent simulation of the annual energy performances permit the comparison between the adopted solution and the other alternatives. The study points out the possibility of achieving significant energy savings.

Keywords: historic building, heat pump, renovation, lagoon water, renewable energy sources, energy efficiency, Venice.
\end{abstract}

\section{Introduction}

The European Union officially adopted a 20-20-20 Renewable Energy Directive setting climate change reduction goals for the next decade [1]. By 2020 the 
targets call for a $20 \%$ reduction in greenhouse gas emissions compared with 1990 levels, a $20 \%$ cut in energy consumption through improved energy efficiency and a $20 \%$ increase in the use of renewable energy. The successive recast of the Energy Performance Building Directive (EPBD) in 2009 [2], has focused in the building energy consumption the most important sector where to act in order to achieve these goals. The new directive lays down mandatory national targets to be achieved by the member states through promoting the use of renewable energy sources (RES) to supply a considerable quota of the building energy requirement. For this aim the EPBD directive considers the heat pump as a renewable energy technology. In fact the aerothermal, geothermal or hydrothermal energy that the heat pump can withdraw from the outdoor ambient is considered renewable energy. This opportunity can be particularly important in the case of interventions in historical buildings subjected to preservation restrictions. Here the use of renewable energy requires much more design effort as the most diffuse alternative sources are often not available. For example solar thermal or PV plants are normally forbidden by monumental preservation. Especially in this case it is therefore necessary to address the attention to the other renewable energy sources between those that the specific environmental context offers. However these solutions are often less frequent and without enough experience especially in the local area. An investigation about their possibilities and limits is therefore fundamental.

In this work a study case is described about the installation of a heat pump coupled with the use of lagoon water in the renovation of the Crucifers Convent, an historical building in Venice subjected to preservation bounds. The availability of surface waters with an adequate renewal circulation due to the proximity of the building to the open lagoon pond permits to foresee interesting thermal level for the machine. Instead in Venice the use of ground water is normally not allowed because of subsidence fears. Besides, the installation of a ground source heat pump is not possible here as the great capacity of the machine requires for the ground exchanger construction a large area unavailable within this compound.

The authors of this paper have drawn up the executive project of the plants and they are now engaged in the construction management. The results of a preliminary study by simulation are presented here. This analysis was carried on to optimize the design of the heat pump installation and to assess its real contribution in terms of energy saving and exploitation of renewable energy sources.

\section{The renovation of the Crucifers Convent}

For its history and architectural value the Crucifers complex is subjected to heavy monumental preservation restrictions. The convent and hospital was founded in the middle of the 12th century by the order of Crucifers along the church of Santa Maria Assunta to aid and to give shelter to pilgrims and crusaders on their way to the Holy Land. It was then rebuilt after fires in 1214 and 1514 , acquired by the Jesuits in 1657 following the suppression of the 
Crucifers order. When the Jesuits were suppressed in 1773 the monastery became a school and then, in 1808, a barrack. The Jesuits returned in 1844 and still occupy the convent parts to the North of the church. Those to the South were used as a barrack until 1990. An aerial photo of the Southern part of the convent is shown in fig. 1 .

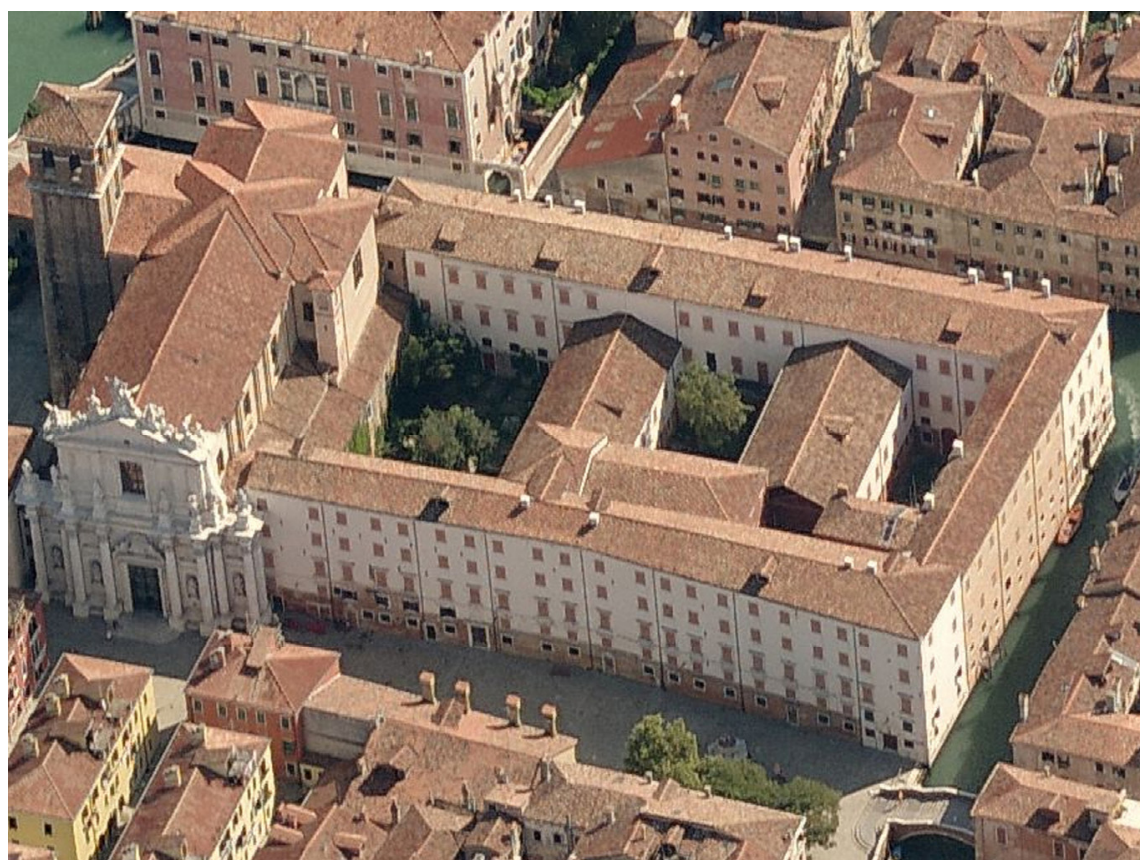

Figure 1: An aerial photo of the Southern part of the Crucifers Convent.

This Southern part is the object of the actual intervention of renovation and new destination for university housing for students and visiting professors and ancillary services. As shown in fig. 2 it presents two cloisters on the left side and two further smaller service courtyards on the right side of the complex. In the middle of each cloister there is a well as it can be seen in fig. 3a) for the main cloister. Each well is connected to an underground cistern that collects rainwater from the above courtyard through a filtration system based on purposely placed sand. This is the old typical water supply system in Venice, derived from the ancient Romans, imposed by the inability to use for human needs the local natural acquifers contaminated by saline waters. The exigency to preserve this historic testimony and the aim to reuse this real sustainable practice prevent the installation of any plant system or new hydraulic grid above or below the cloister courtyards. Instead in the other smaller courtyards new installations are permitted in underground spaces where there are not important archeological presences. In the frontal side towards Campo dei Gesuiti the main entrances are located, the back side is lapped by the channel Rio dei Gesuiti as shown in 
fig. 3b). On the left we have the church of Santa Maria and on the right side the limit is a minor channel. The complex presents three long buildings (the sleeves) along the perimeter area and they have a total height of $26 \mathrm{~m}$. Two other lower buildings are located in the central part and they surround the cloisters and courtyards. Normally the ground floors are used for various services, while the upper floors are divided into the residential units.

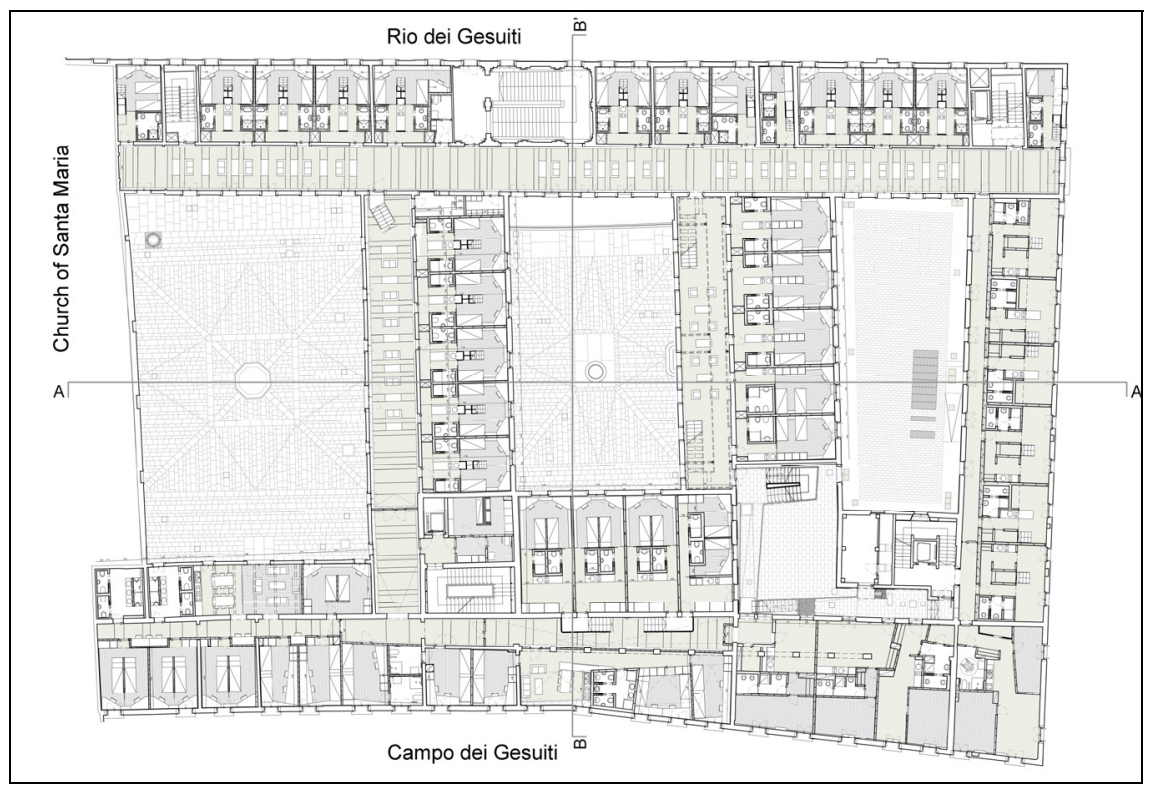

Figure 2: $\quad$ A plant view of the intervention area

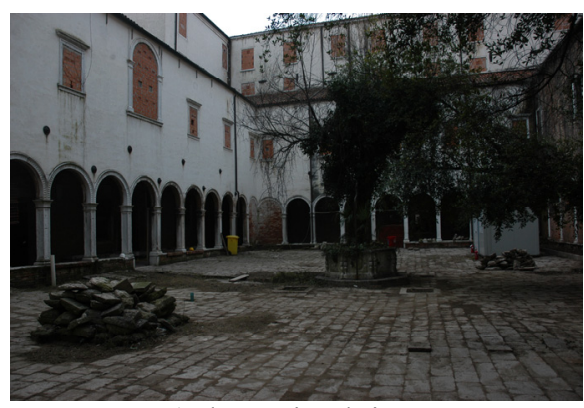

a) the main cloister

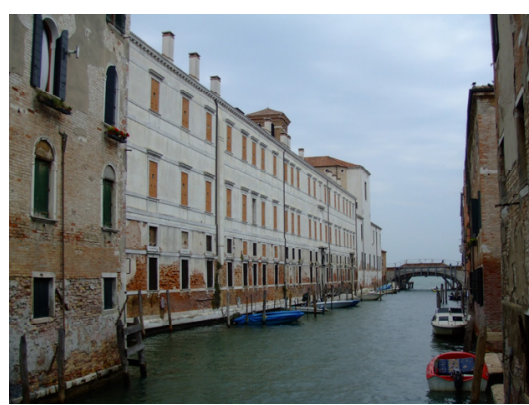

b) the channel Rio dei Gesuiti

Figure 3: Views of the Crucifers Convent.

The building sections reported in fig. 4 show a height greater than $6 \mathrm{~m}$ in each floor of the sleeves and this fact has permitted the realization of mezzanines where to locate the beds of the rooms while the adjacent long corridors are used 
as recreational and meeting areas. The project foresees the creation of 177 apartments for students, each of them with two bed places, independent bathroom, kitchen and study area. Further greater 32 residential units will be reserved for visiting professors. Facilities like laundry, meeting rooms, classrooms and workshop rooms will be at the disposal of the internal guests. While community services: bar, restaurant and relative kitchen with 100 places, gym, computer room and a library, will be open also to the city community. The heating, ventilating and air conditioning (HVAC) plants have been chosen to be supplied by low temperature water $\left(40-45^{\circ} \mathrm{C}\right.$ in heating mode) to permit a satisfactory use of the heat pump. In the residential unit the HVAC plants consist of fan coils embedded in the furnishings and a controlled ventilation system with delivery in the room and aspiration in the bathrooms. The centralized ventilation system allows an efficient heat recovery from exhaust air to preheat the fresh air. Each residential unit is automatically excluded from ventilation grid in the absence of people inside the room and the total air flow rate is controlled by inverters which act on fan motors. In the greater rooms at the ground floor level HVAC plants are based on fan coils and primary air distribution ducts. Particular effort requires the HVAC installation in presence of painted walls. In some area there is also the contribution of radiant panels when there are no preservation restrictions on the floor. But the impossibility of a generalized use of radiant panels prevents a supply water thermal level more favorable $\left(30-35^{\circ} \mathrm{C}\right)$

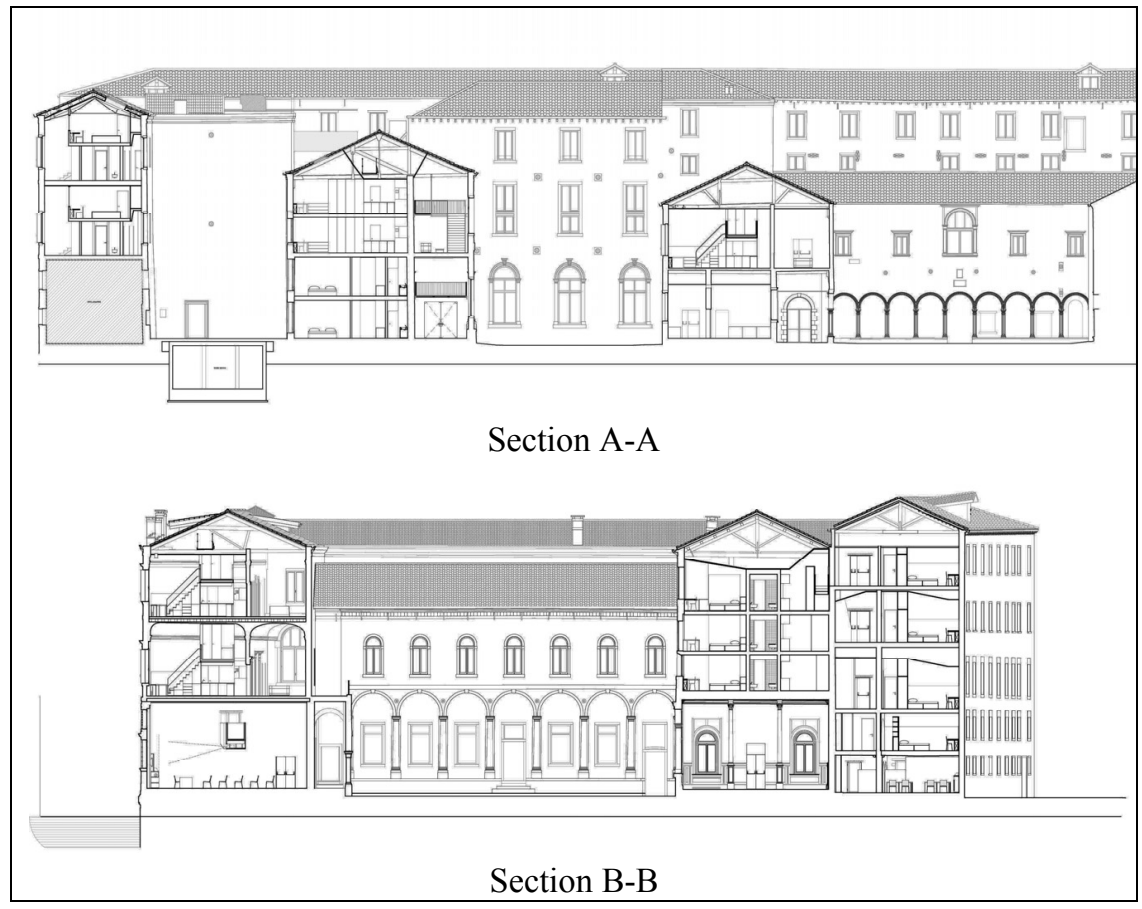

Figure 4: Sections of the buildings. 
for the heat pump. The technical centrals are located in the tower between the two courtyards on the right side and in underground rooms specially dug under these two courtyards. In the tower we have the installation of the reversible water to water heat pump used to produce hot water for heating and chilled water for air conditioning in summer. The lagoon water is withdrawn from the channel Rio dei Gesuiti. The point of suction is on the left side and the refund is in the same channel but on the right side about $50 \mathrm{~m}$ far. In fact, as shown in fig. $3 \mathrm{~b}$ ), this channel has a sufficient dimension to ensure an adequate water flow rate and the sampling location is near the mouth unto the open lagoon. This is important because the surface waters might be profitably and safely supplied for the whole year just in buildings close to the main canals or in open lagoon whereas in the other canals low water volume changes per day take place, so thermal saturation of the local water reservoir might be reached.

In fig. 5 a functional diagram of the heat pump installation is illustrated. The reversible electric water-water heat pump has a declared heating capacity of $610 \mathrm{~kW}$ at entering-leaving evaporator water temperatures of $7-4^{\circ} \mathrm{C}$ while user supply hot water temperatures ranging from 40 to $45^{\circ} \mathrm{C}$. In cooling mode its nominal capacity is $580 \mathrm{~kW}$, at entering-leaving condenser water temperatures of $30-35^{\circ} \mathrm{C}$ and a user supply chilled water temperatures ranging from 12 to $7^{\circ} \mathrm{C}$.

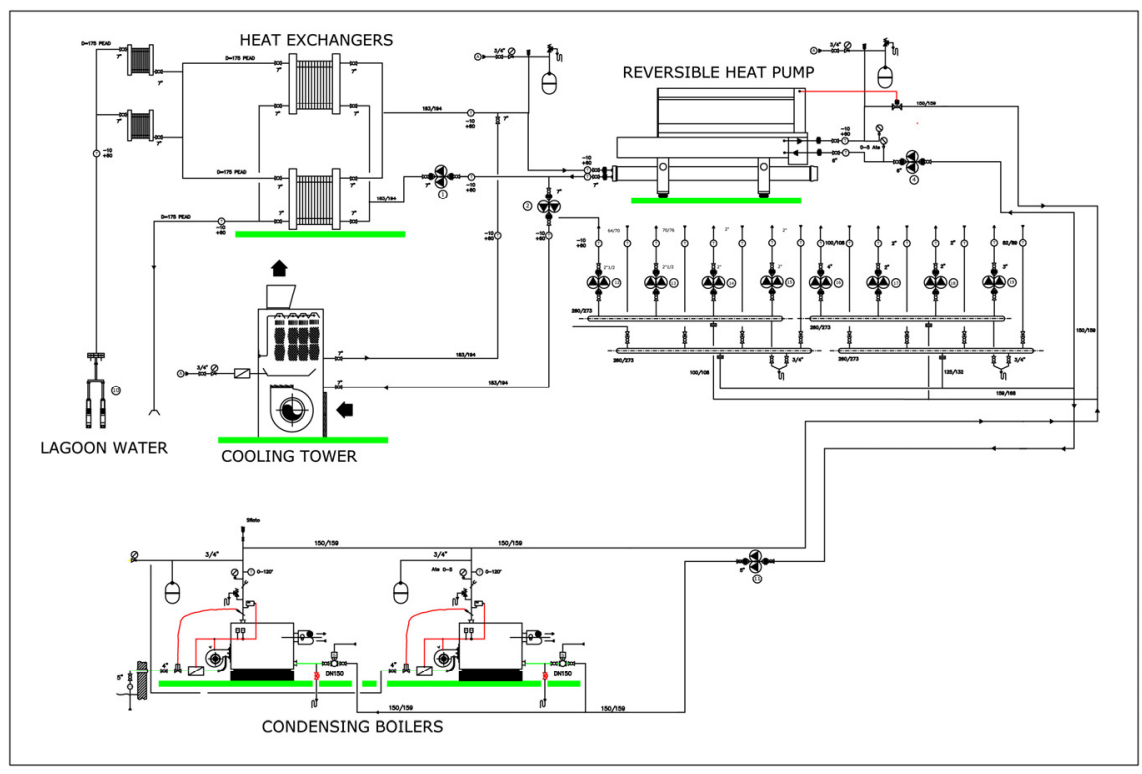

Figure 5: The functional diagram of the lagoon water source heat pump.

A plate heat exchanger is interposed between the circuit sampling lagoon water and the heat pump circuit in order to avoid the fouling of the heat exchangers inside the machine. In winter the minimum operating conditions of the thermal level of the lagoon water is $8^{\circ} \mathrm{C}$ inlet and consequently $5^{\circ} \mathrm{C}$ outlet. The heat exchanger sizing permits in these conditions the previous thermal 
difference $7-4^{\circ} \mathrm{C}$ in the evaporator circuit. This limit has been chosen in order to obtain high efficiency of the machine and to avoid the necessity of antifreeze mixtures which penalize the heat pump performances. Therefore when the lagoon water temperature is below $8^{\circ} \mathrm{C}$, the heat pump does not work and the heat requirement is supplied by auxiliary condensing boilers. In the same way in cooling mode, the maximum operating inlet-outlet thermal levels of the lagoon water is $27-30^{\circ} \mathrm{C}$ which corresponds to the previous inlet-outlet water thermal levels $30-35^{\circ} \mathrm{C}$ at the condenser. In fact the law regulations about the thermal use of the surface waters impose a maximum raise of the water of $3^{\circ} \mathrm{C}$ and a maximum temperature level of $30^{\circ} \mathrm{C}$. In summer when these values are exceeded it is mandatory to stop the use of the lagoon water. In this event the intervention of a water cooling tower ensures anyway the working of the refrigeration machine. The reversible heat pump has two independent refrigeration circuits, each with one screw compressor. The refrigerant fluid is R113a. For the comparison with the air source, a corresponding air-water heat pump has been used. Referring to models at present available in the market, no commercial machines with this high capacity present modulating control by inverter. Therefore the two heat pumps have a capacity control only based on simple modulating box for the screw compressors. There are two plate heat exchangers, working in an alternative way, to allow periodic cleaning without interrupting the service. They are made in titanium to resist the aggression of saline waters. The heat exchangers are preceded by an efficient self-cleaning filtering system as the lagoon water in the channels is normally very dirty.

\section{The investigation of the energy performances}

The reversible heat pump is dedicated only to supply the climatization demand. The production of domestic hot water (DHW) during the whole year is not considered in this memory. In fact the plant design foresees the installation of an independent cogeneration system whose heat recovery is expressly sized to satisfy the heat demand for the production of DHW which is stored in two great tanks. This production is eventually assisted by the auxiliary condensing boilers.

The law regulations impose in Venice a heating season from October 15 to April 15, the air conditioning is normally from June to September. The assessment of the seasonal performances has been obtained by computer simulation of the building-plant system for three heating seasons, from 20042005 to 2006-2007, and four summers from 2004 to 2007. The meteorological data necessary for the analysis have been provided by local meteorological stations. In particular the necessary values of lagoon water temperatures come from a recording unit in proximity of the Rio dei Gesuiti.

This weather sequence is formed by two similar winters quite colder than the average followed by a third winter clearly milder. The four summers are quite similar one another. In figs. 6 and 7 the trends of the temperatures of the water and of the outside air are reported for summer 2007 and winter 2006-07 respectively. The comparison shows the effect of the water inertia which reduces the hourly oscillation of the water temperature with respect to the outside air. 
Anyway the thermal levels of the lagoon water appear less favorable and more variable than expected when compared with well water (constant $13-15^{\circ} \mathrm{C}$ ) or offshore water.

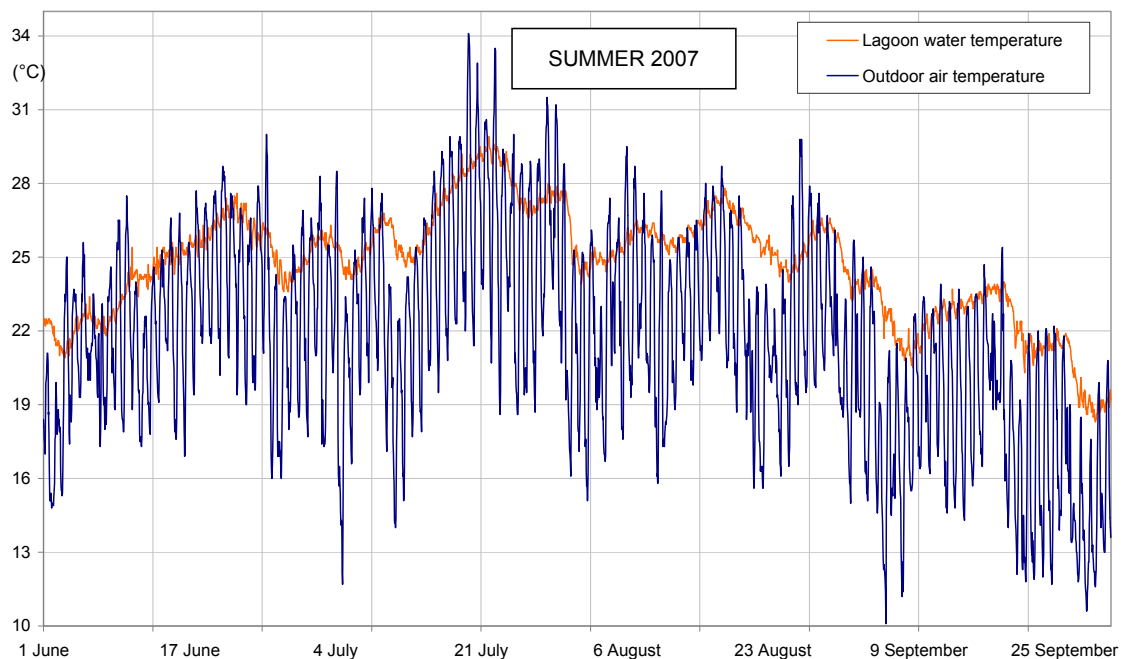

Figure 6: Outdoor air and lagoon water temperatures in the summer of 2007.

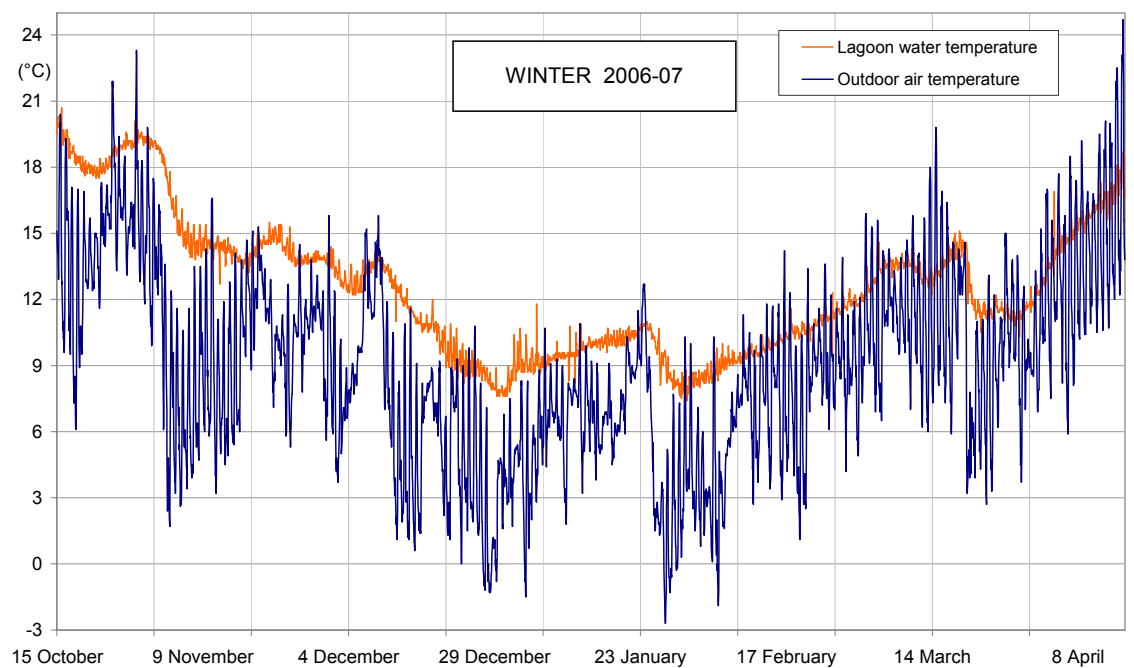

Figure 7: Outdoor air and lagoon water temperatures in the winter of 2006-7.

The penalizing effect of a limited circulation of sea currents in the lagoon is certainly important. This is particularly evident in summer when in the hottest 
period the lagoon water can arrive over $27^{\circ} \mathrm{C}$ as shown in fig. 8 imposing the alternative use of the cooling tower. Instead in the winter 2006-2007 (fig.7) the water temperature never goes below the operating limit of $8^{\circ} \mathrm{C}$. However in the two previous cold winters the heat pump stop hours were respectively the $12 \%$ and $13 \%$ of the total amount of the working hours. In the four summers the same seasonal value is between $1 \%$ and $6 \%$.

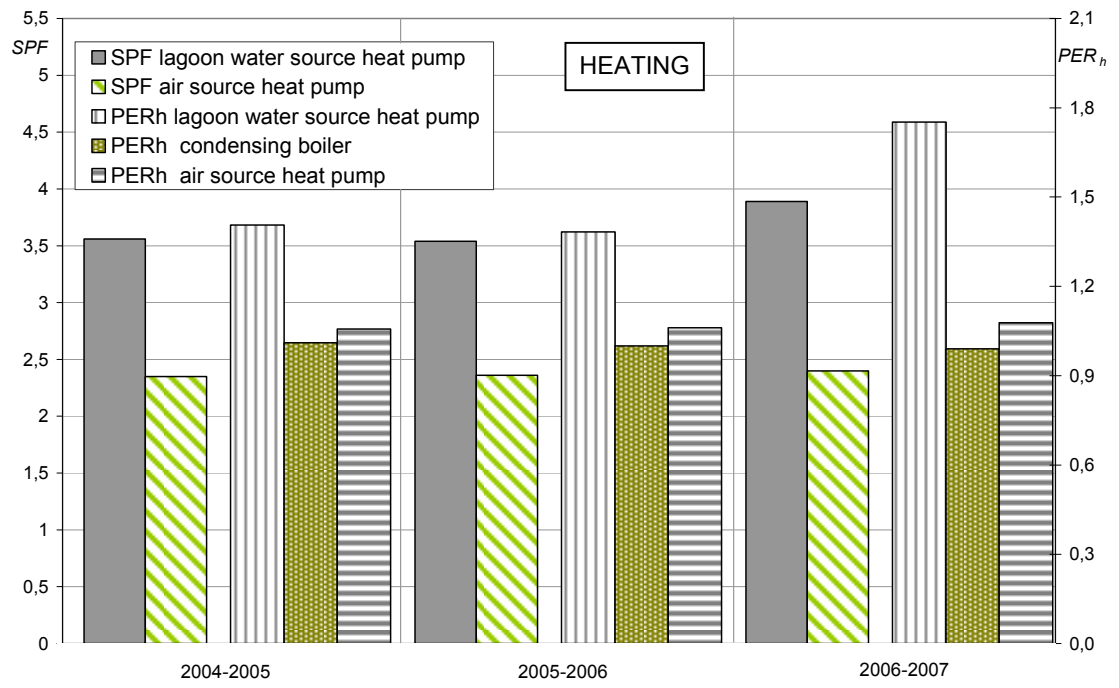

Figure 8: $\quad$ Seasonal performance factor $S P F$ of the heat pump and primary energy ratio $P E R_{h}$ of the investigated solutions in the three winters.

By the simulation a comparison between three possible plant alternatives for the production of heat and cold requirements for the building climatization has been carried on: the lagoon water source heat pump assisted by cooling towers and condensing boilers, an air source heat pump and the traditional solution with only condensing boilers in winter and an air cooled chiller in summer. For this investigation adequate models of the Crucifers complex and of the plant components have been elaborated.

In particular the efficiency of the heat pump is calculated on hourly basis as a function of the thermal levels of the external fluids exchanging heat at the evaporator and condenser taking into account also the behavior of the machine in part load working conditions (Gastaldello and Schibuola [3]). Analogous method is used for the condensing boilers (Lazzarin et al. [4]). The building loads are calculated by EnergyPlus program (Crawley et al. [5]), assuming a typical scheduling for the internal loads, occupancy, lighting. The seasonal simulations have given the mean efficiency calculated as the ratio of the total heat (or cold) provided to the total electric consumption of the heat pump in the same period. For the heating mode this mean efficiency is indicated as SPF (Seasonal Performance Factor) as named in the $E P B D$ directive. For the cooling mode it is 
named Seasonal Energy Efficiency Ratio (SEER) as usual in technical literature. Another efficiency index is the Primary Energy Ratio $(P E R)$ that is the ratio of the energy delivered to the primary energy consumption of the plant, auxiliaries included. To calculate this primary energy consumption, the Italian official value 2.22 of the primary energy factor for the end-user electricity has been used. In the case of the lagoon water source heat pump, the contributions of the auxiliary condensing boilers in winter and of the cooling tower in summer have been taken into account. In figs. 8 and 9 these seasonal efficiencies and indexes are reported for the analyzed winter and summer periods respectively. $P E R_{h}$ is referred to the heating mode and $P E R_{c}$ to the cooling one. The simulation results indicate a net superiority of the solution with the lagoon water especially during the winter period owing to the favorable water thermal levels.

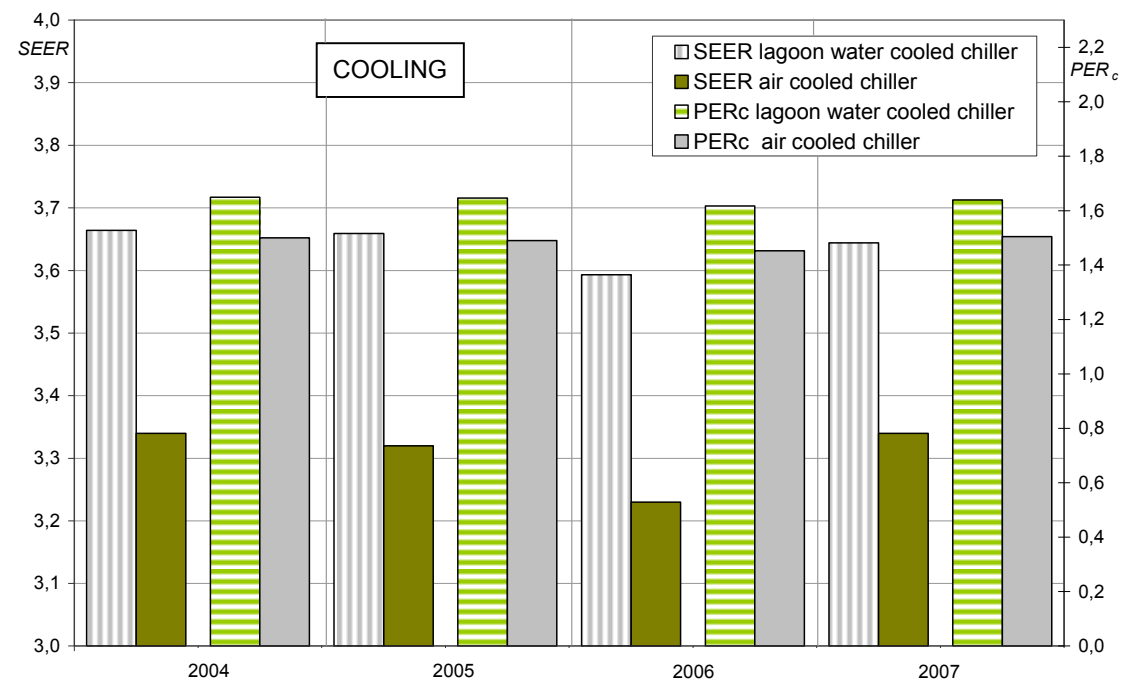

Figure 9: Seasonal energy efficiency ratio SEER of the two heat pumps in chiller working and primary energy ratio $P E R_{c}$ in the four summers.

Fig. 10 shows the primary energy savings with the two reversible heat pumps in the heating period and annual for the three years. Here, in order to avoid breaking the winter seasons, each year is from October 15 to the same date of the following year.

This saving is referring to the primary energy consumption for climatization in the case of the traditional plant with condensing boilers and air cooled chiller.

The savings are most remarkable in winter and therefore the annual values attenuated by the summer behavior. At annual level the energy saving and the corresponding reduction in greenhouse gas emissions are always maintained over $20 \%$ with a three years average more than $24 \%$. 


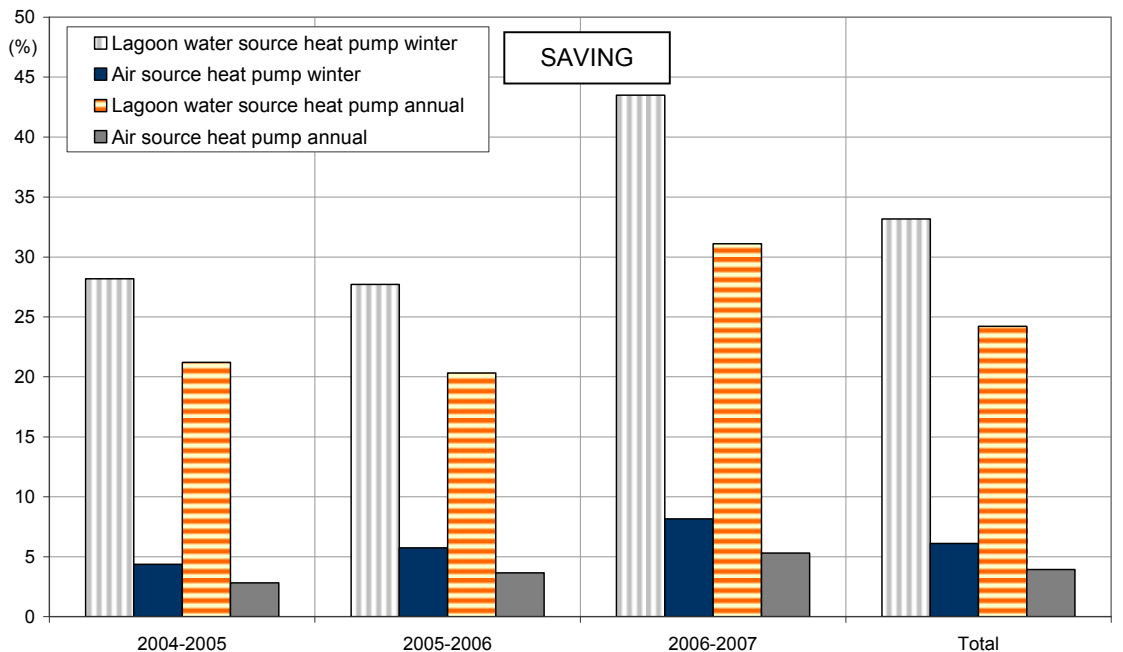

Figure 10: Heating period and annual primary energy savings (\%) for three years and for the whole period. The saving is referred to the primary energy consumption for climatization with the traditional plant.

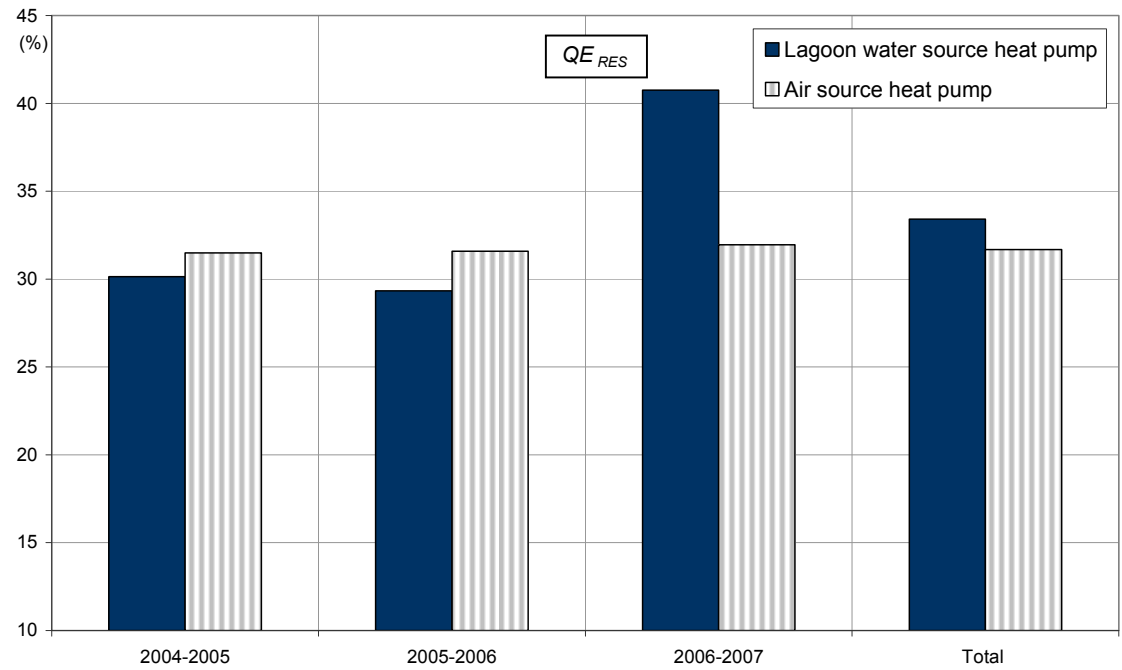

Figure 11: Renewable energy quota $Q E_{R E S}(\%)$ for three years and for the whole period for the two heat pumps. This is referred to the annual energy demand for climatization. 
The RES exploitation quotas $Q E_{R E S}$ referring to the total annual energy demand for climatization are compared in fig. 11 for the two reversible heat pumps. As required by EPBD only the aerothermal or hydrothermal energy taken by the heat pump in heating mode can be considered for this quota. In terms of RES contribution the air source heat pump has high performances too because its working has no limitations. On the contrary a low lagoon water temperature can impose the intervention of the condensing boilers with no RES exploitation. Nevertheless with the lagoon water the mean annual $Q E_{R E S}$ results always over $25 \%$, with an average of $33 \%$ in the three years.

\section{Conclusions}

The study has shown remarkable application opportunities for the use of the reversible heat pump coupled with the lagoon water in Venice. Even referring to commercial machines not particularly efficient in terms of capacity control and end-user supply thermal levels, the lagoon water solution permits to achieve seasonal efficiencies very interesting.

The energy savings is over $20 \%$ with respect to traditional plants and they are clearly better than those obtained by the air source heat pump.

Thanks to the lagoon water the RES exploitation is possible in this historic building despite it is subject to heavy preservation restrictions.

In this way also this retrofitting intervention in a monumental building will be able to contribute to hit the 20-20-20 targets by 2020 .

\section{References}

[1] EU Community, Climate and Energy package: 20-20-20 targets, December 2008.

[2] EU Community, Energy Performance Building Directive EPBD (recast), directive 2009/28/EC, April 2009.

[3] Gastaldello A., Schibuola L., A proposal for an European standard to calculate the seasonal efficiency of inverse cycle machines in building climatization, Proc. of the 8th REHVA World Congress, Clima 2005 Losanna, Switzerland, pp. 132-140, 2005.

[4] R. Lazzarin, F. Busato, F. Minchio, Performance analysis of different applications for condensing boiler on residential buildings in several climatic areas, Proc. of the 3rd International Conference on Sustainable Energy Technologies, 2004, Nottingham (UK).

[5] Crawley, B. D., Lawrie, K. L., Winkelmann, F. C., Pedersen C.O., EnergyPlus: new capabilities in a whole-building energy simulation program, the $7^{\text {th }}$ Int. Conf. of the International Building Performance Simulation Association (IBPSA), Rio de Janeiro, Brazil, pp. 51-58, 2001. 